\title{
Editorial.
}

\section{The SECTIONS of LARYNGOLOGY and OTOLOGY in the INTERNATIONAL MEDICAL CONGRESS AT ROME.}

VARIOUS opinions have been rife as to the excellence or otherwise of the general arrangements connected with the Congress, but as regards those sections, at least, with which we are particularly concerned, it would be difficult to find any serious fault. The meetings were under the responsible presidency of Profs. MASSEI and DE ROSSI respectively, who performed their duties with the utmost devotion, energy, courtesy, and geniality, along with the Honorary President for each day. The names of those occupying the various offices are given on pages 231 and 265 and are sufficiently familiar to our reaciers.

These sections were well attended, and, as will be seen from the reports of the papers and discussions, the assemblies both of laryngologists and otologists were in certain respects highly representative ones. A striking exception to this rule was afforded by the English-speaking practitioners of the specialties, of whom extremely few contributed papers or attended the meetings. The English language was hardly heard, and the proceedings were accordingly carried on in French, German, and Italian, so that to anyone who had only a moderate knowledge of those three languages the effort of attention was necessarily most fatiguing, and those who knew only one of them lost too much of the matter to encourage them to remain. This drawback to international congresses is, and for long hence must be, inevitable, and with the view of supplying our English-speaking readers with as full a report as possible of the proceedings, we have at considerable expense and with no little labour procured copies of the papers and discussions in their original languages and translated them into our own. This month we present a large first instalment, containing a full account of the work of the first two days. This includes the Inaugural Addresses of both Presidents, that of Prof. MASSEI taking the more pretentious form. After referring feelingly to the deaths of many of the most valued contributors to laryngology-including the late co-editor and joint founder (with Dr. NORRIS WOLFENDEN) of this Journal, Sir Morell Mackenzie, as also the non-professional but scientific and original worker, EMIL BEHNKE-he described the the whition of laryngology to general medicine, not as a fraction of it, but as the whole and something more. An ideal to strive for and, within reasonable limits, to be attained.

Dr. SENDZIAK's observations on "Follicular Angina" are founded on 
honest investigation by this esteemed contributor to our pages. "1'achydermia Laryngis" and "Fibroma of the Vocal Cords" are discussed by Prof. Chiari. The discussion on "Vibratory Massage" will be read with interest, and whether the views of the enthusiastic introducer, Dr. Braun, of Trieste, be accepted with conviction or not, they are bound to command attentive consideration, Prof. CHIARI'S unfavourable decision notwithstanding.

The value attached to electrolysis as a therapeutic agent in laryngology and rhinology is illustrated by Prof. CHIARI's paper on "Pachydermia Laryngis" and Dr. MOURE's on the "Comparison between Electrolysis and other Modes of Treatment for the Destruction of Spurs and Deviations of the Nasal Septum."

Among the otological subjects discussed we may note Prof. Moos's case of "Thrombosis of the Lateral Sinus," in which the clinical features were atypical, the nature of the case being revealed by the post-mortem examination. This form of confirmation would have added considerably to the value of Dr. MOURE's case of "Otitic Cerebral Abscess" with a latent course ending in unexpected sudden death, and in which no autopsy was obtainable. These valuable additions to our knowledge of the sequelæ of suppurative median otitis are most instructive, if not exactly reassuring. Dr. REINHARDT's important paper in support of "The Surgical Treatment of Cholesteatoma" and the discussion on it may be studied with advantage. Prof. PoLiTzer related one of his solid additions to aural pathology, an osteitic "Affection of the Labyrinthine Capsule." The preparations shown by him and by Prof. Moos were models of anatomical work. Profs. Gradenigo, Cozzolino, GRAZZI, and other well-known Italian otologists brought forward important subjects during the first two days, as also did Drs. GELLÉ, of Paris, and Colladon, of Geneva.

In our further reports we shall be able to place before our readers important papers on the "Surgical Treatment of Tuberculosis of the Larynx," "Latent Empyema of the Maxillary Sinuses," "Extraction of the Auditory Ossicles," and other subjects of laryngological and otological interest.

If no sensational epoch-making work has been brought forward, there has been ample evidence of emulative industry and of steady advance all along the line.

We are greatly indebted to Dr. ST. CLAIR THOMSON, of London, for the translation of the bulk of the Italian portion of these reports. The German has been undertaken by Dr. Macintyre, the French by Dr. WOLFENDEN, and for parts of each and for the general arrangement Dr. Dundas Grant is responsible. 